\title{
Solar exposure condition improvement in urban area using light guide
}

\author{
Denis Gritsiyenko ${ }^{1, *}$, Vitaliy Kasyanov ${ }^{1}$ \\ ${ }^{1}$ Moscow State University of Civil Engineering, Yaroslavskoe shosse, 26, Moscow, 129337, Russia
}

\begin{abstract}
This article provides an overview of the light guides and lighting systems used to improve the natural lighting conditions of the premises with insufficient lighting comfort. The retrospective of occurrence of the light guides from the 19th century to the present time is shown. The relationship between the modern light guides and light-guide and other lighting systems that have been developed since the middle of the 19th century is demonstrated. The relevance of the use of light guides during the construction and reconstruction of urban buildings is considered. The article describes the classification of light guides developed by the author, and shows the classification of light guides proposed by Aizenberg J.B. For the first time it was proposed to use light guides to improve the conditions of solar exposure of the shaded buildings. The example of two buildings shows a scheme for the use of light guides to improve the solar exposure conditions of the shaded buildings of the urban area. Setting of the tasks to be carried out to consider the use of the light guides in order to improve insolation conditions is completed.
\end{abstract}

\section{Introduction}

Even in ancient Egypt, the solar irradiation was used to illuminate the premises of the pyramids. In 1850, French photographer Paul Emile Chappuis first patented various types of reflectors that can redirect sunlight into the building mainly to the ground and basement floors. The flier of 1851 of the patented reflectors with the slogan: "Excellent daylight! Why do we burn gas?"(Figure 1) is presented below [1].

\footnotetext{
*Corresponding author: denis.gritsiyenko@gmail.com
} 


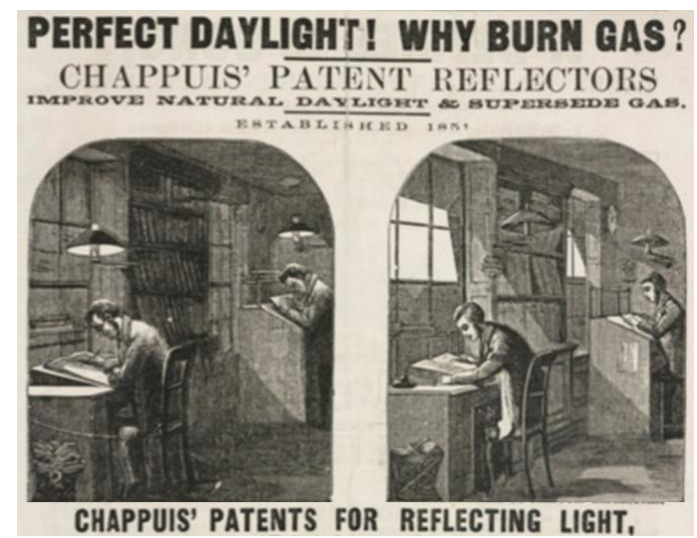

Fig. 1. The flier of the daylight reflectors patented in 1850 by Paul Emile Chappuis.

In addition, it is worth noting that these patents were the prototype of the modern Swiss Heliobus ${ }^{\circledR}$ system (Figure 2) [2]. This system allows providing the solar radiation to the ground and basement floors of the buildings. One of the advantages of this system is its passivity, and its maintenance requires minimum amount of money and energy.
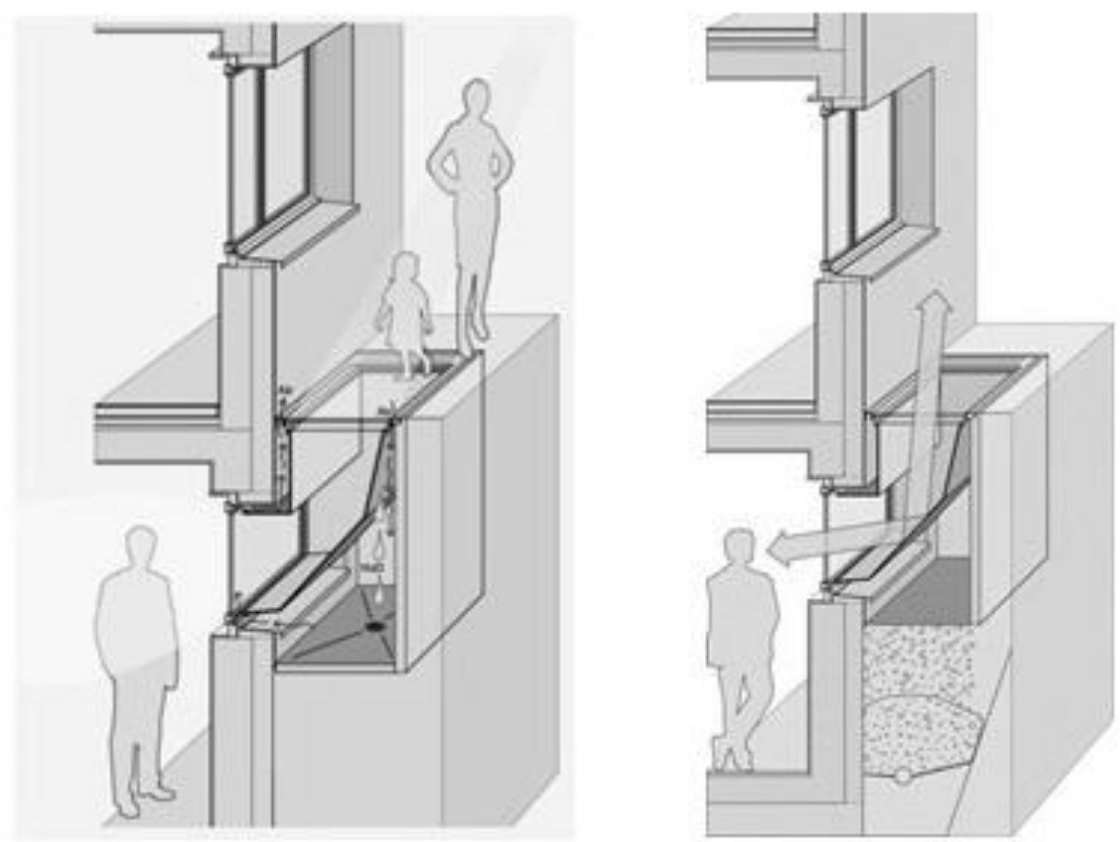

Fig. 2. Swiss system Heliobus ${ }^{\circledR}$ for transportation of the solar radiation to the ground and basement floors of the building.

In $1881 \mathrm{~W}$. Wheeler patented a device for artificial illumination of living accommodations and other premises (Figure 3) [3]. 


\section{W. WHEELER.}

APPARATUS FOR LIGHTING DWELIINGS OR OTHER STRUCTURES. No. 247,229 . Patented Sept. 20, 1881 .

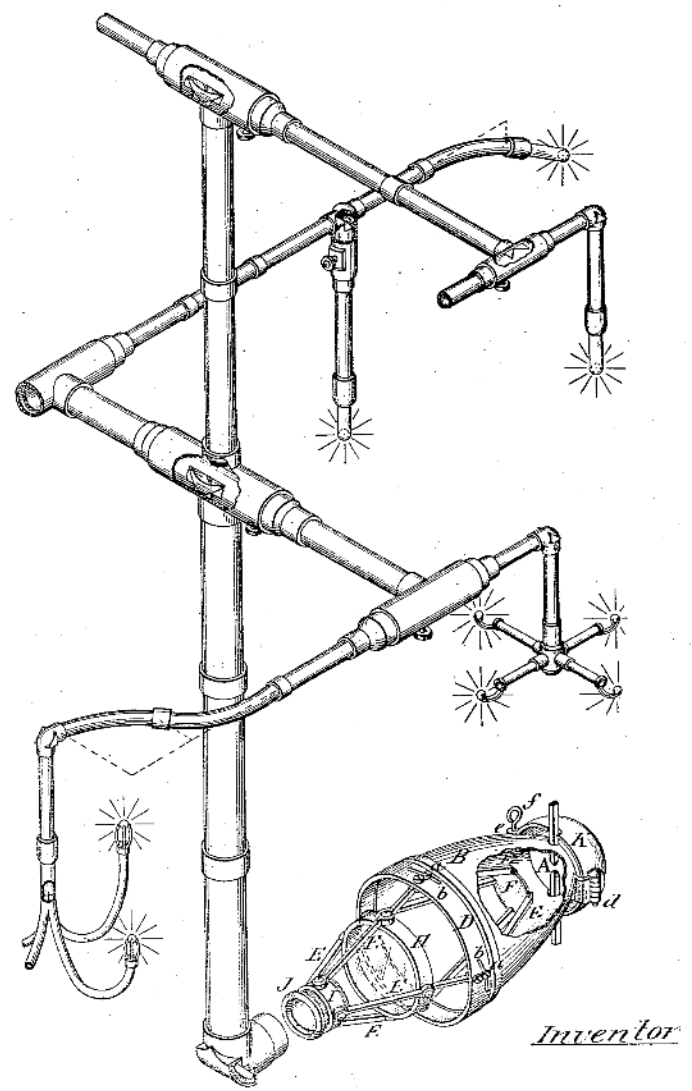

Fig. 3. The device for the radiation distribution from the lamp inside the house, patented in the USA in 1881 by W. Wheeler.

If the solar radiation were a radiation source, this unit could transport the solar radiation inside the buildings.

In 1887 V.N. Chikolev built the first plant in Russia with the use of light guides for lighting of the building of prismatic presses of Okhta gunpowder factory. Inside the building, there were taps at $90^{\circ}$ on the light guides, with terminals in the form of hemispheres made of opal glass. In front of the taps in the light guide at an angle of $45^{\circ}$ to the axis there were reflecting mirrors that redirected artificial light to the premises. (Figure 4) [4]. 


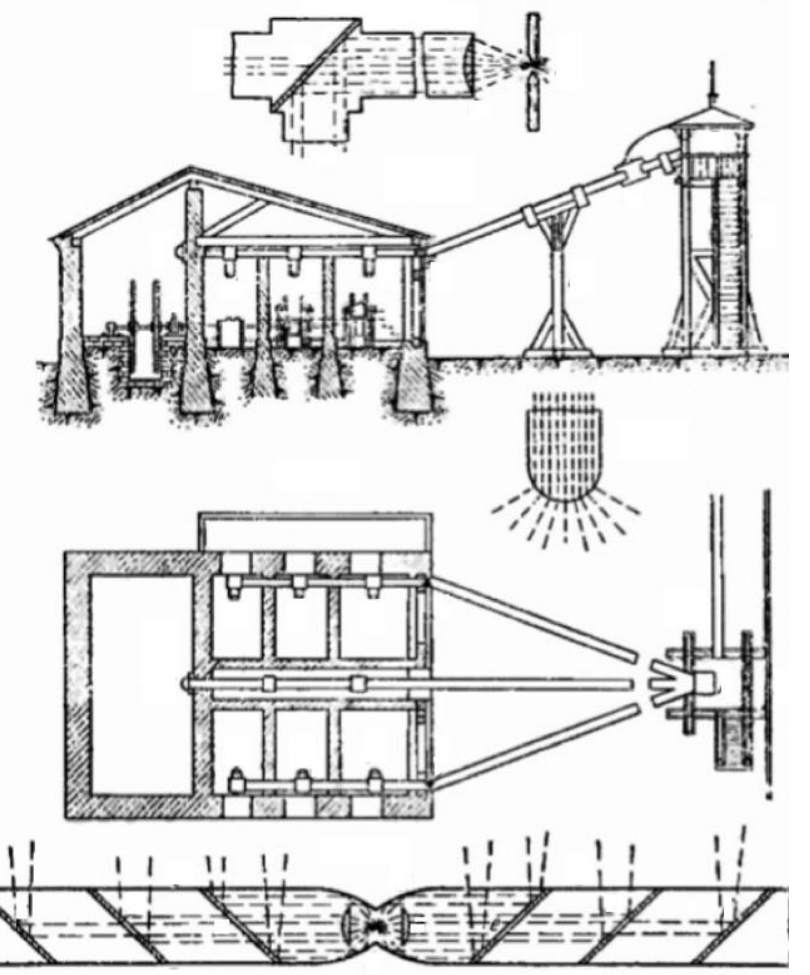

Fig. 4. The experimental scheme of the light guides constructed by V.N. Chikolev for artificial illumination of the prismatic presses premises of the building of Okhta gunpowder factory in 1887 .

This plant could also use the solar radiation as a light source. Daniel Colladon in 1841 first showed the audience the effect of total internal reflection through the water jet, using a lamp, and a tank with water (Figure 5). The light was too faint because of poor development of lighting equipment at that time. Then Daniel Colladon focused the solar radiation through a lens and directed it along the falling curving jet. The effect was stunning - the sun beams curved along the falling water jets [5]. This phenomenon is a prime example of the light guide, working on the principle of total internal reflection.

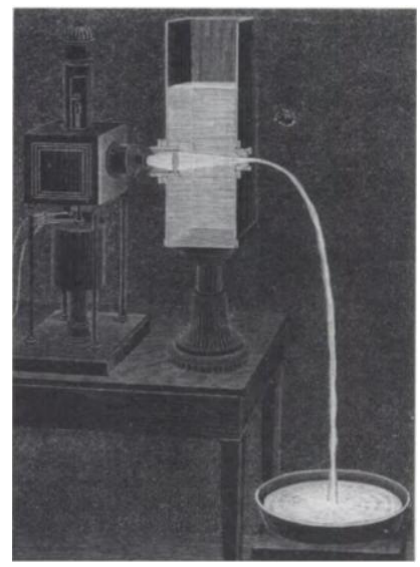

Fig. 5. Daniel Colladon's plant. 
In 1870, a scientist from England, John Tyndall at the Royal meeting, re-conducted the experiment, previously held by Daniel, and showed that light can spread along the curving jets of water [6].

This principle works with fiber-optic light guides. The solar radiation entering the light guide spreads along it, curving in the shape of the light guide. This enables the delivery of the solar radiation at distances up to 20 meters. One of the advantages of using such light guides is a relatively small cross-section of the light guides in comparison with the hollow thin-wall light guides (HTL) of Solartube ${ }^{\circledR}$ type, thereby providing light to the premises remote from the sun light without taking the space by heavy-section light guides. One of the disadvantages of using these light guides is impossibility to work without active heliostats. In terms of operating of these plants, it is additional costs for energy as well as for the routine maintenance of such plants.

\section{Classification of the guide lights}

At the top level, the light guides designed to transport solar radiation can be classified into the following structure consisting of HTL and fiber-optic light guides (Figure 6). This scheme includes the existing systems provided by foreign companies, as examples.

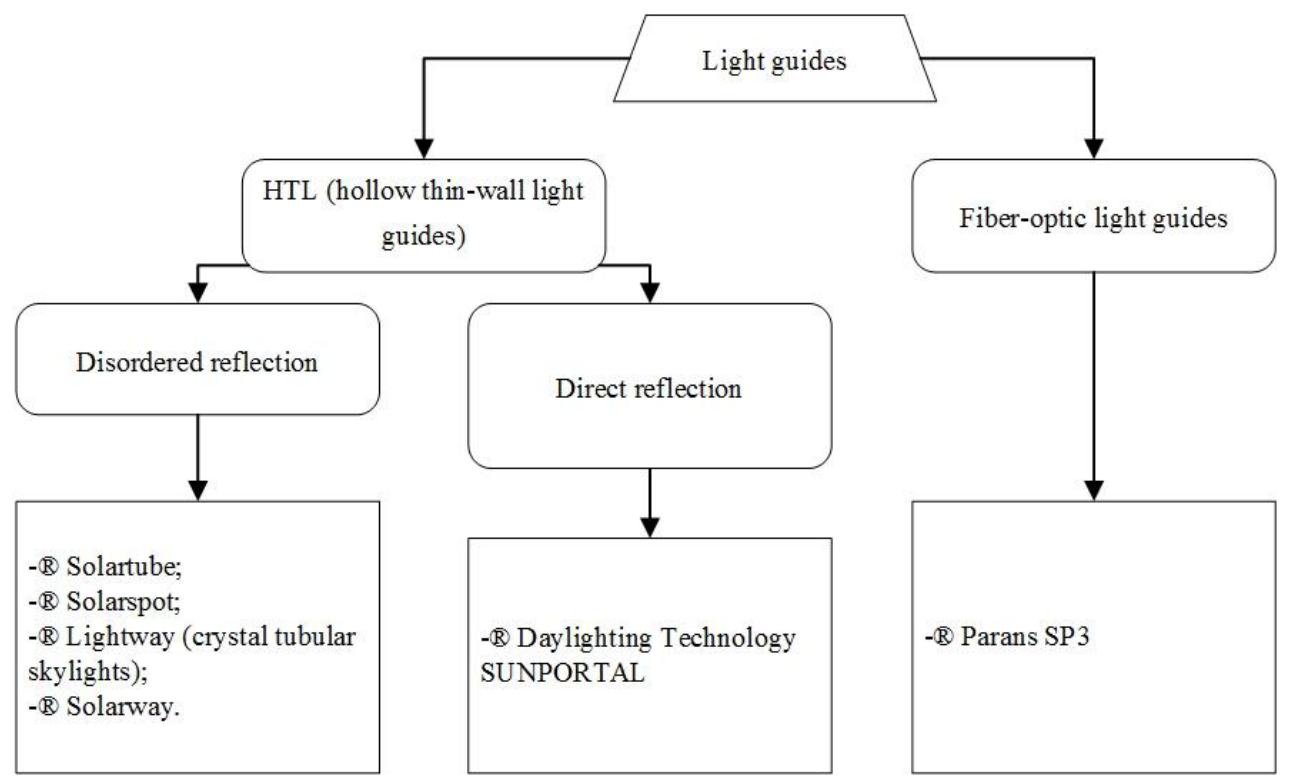

Fig. 6. Classification of the light guides on the upper level with an indication of the existing systems on the market, offered by the author.

J.B. Aizenberg, G.B. Buchmann, A.A. Korobko V.M. Pyatigorskiy [7,8,9] made a great contribution to the development of optical and lighting systems with HTL. Despite the fact that many systems have been designed primarily for artificial lighting, they could be used for solar radiation, and the authors showed this.

Book [10] shows the classification of the systems using HTL (Figure 7). In the late 20 early 21 centuries, HTL were used to improve the conditions of the natural lighting. Today, there is a fairly wide range of technical systems consisting of the light guides $[11,12]$. 


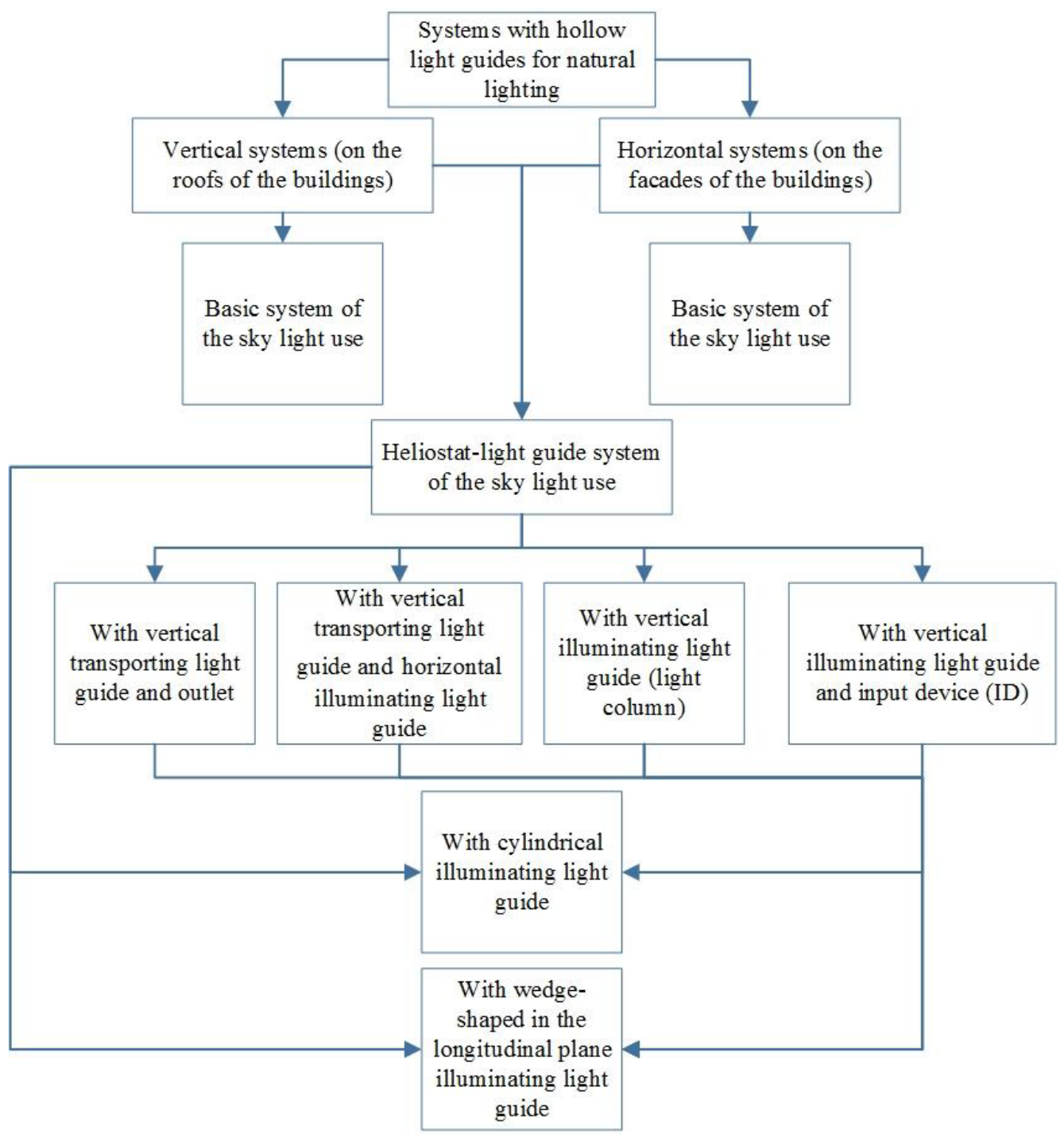

Fig.7. Classification of HTL offered by J. B. Aizenberg.

The article [14] describes the estimate of the use of the active ARTHELIO system using mirrors, heliostat and hollow light guides. Combined natural and artificial lighting, conducted through the hollow light guide through the stairwell of the building in Berlin was estimated. Access of the daylight to ARTHELIO system device was absent. When the sky is clear and sunny the energy saving according to the survey was $64 \%$, at partially cloudy weather $39 \%$, when the weather was cloudy, this system is not effective. It is also worth noting that before the installation of this system the access of the daylight into the stairwell was absent, according to the results of the study, on a sunny day in the period from 10:30$15: 30$, when using this system the artificial lighting system is fully compensated by the natural lighting, and illumination value is significantly higher than the standard value according to German regulatory documents, DIN 5035, 100 lux. To calculate daylight factor using HTL, A.K. Solovyev proposed method of calculating the daylight factor [15]. In the book, the author also notes that the optimal economic benefit in terms of energy savings can be achieved by the combined use of the daylight and artificial illumination. 


\section{The use of the light guides to improve the solar exposure conditions}

Hypothetically, HTL could be used to improve not only natural lighting conditions, but also the solar exposure conditions. In order to improve the light conditions of the shaded areas of urban area, it is possible to use the solar radiation, falling on the solar-exposed southern facades and roofs of the buildings, collect and carry this radiation inside the building, as well as carry through this building on the shaded buildings and areas standing near it. The HTL system can be used for this purpose (Figure 8, 9).

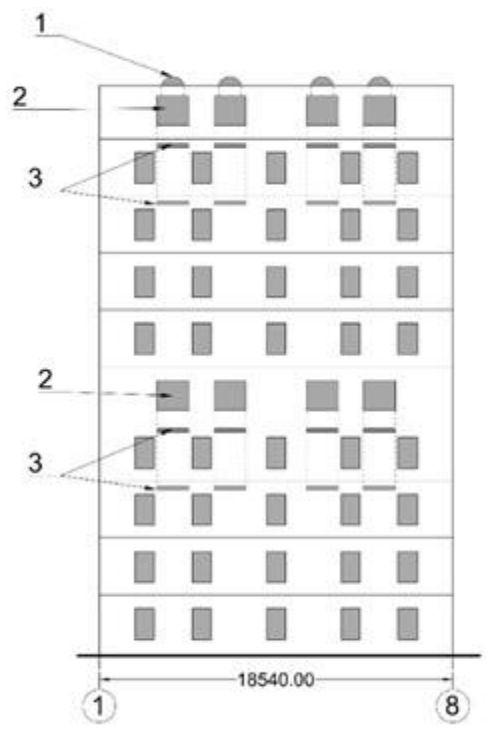

Fig. 8. Facade fragment 1-8 indicating the allocation of vertical and horizontal HTL after reconstruction of the building.

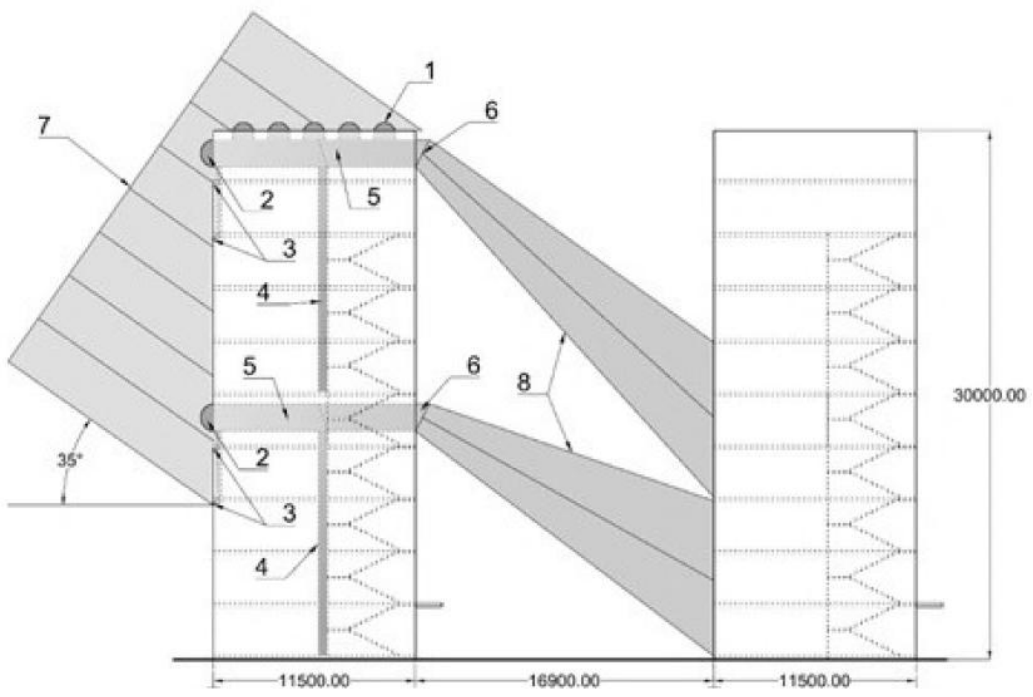

Fig. 9. Sectional view of the buildings with vertical and horizontal HTL system built in one of them, during the reconstruction of the building. 
Figures 8 and 9 show schemes indicating built-in HTL system, which could be installed during the building reconstruction. This system includes input devices for vertical HTL 1, input devices for horizontal HTL 2, input devices for horizontal HTL 3, hollow vertical light guides with a cylindrical illuminating light guide 4, main horizontal HTL 5, side outlets 6, direct incident radiation on March 22, in the latitude of Moscow and Moscow region 7 solar radiation, directed to the shaded facade located to the north, conducted through the light guides 8 . Figure 9 shows that the building section, is shaded by the building located to the south. The solar radiation does not reach floors 1-6 on the facade of the building located to the north in the days of equinoxes. The installation of the light guides could improve the light conditions of the building in this area, using the intensive solar radiation falling on the south facade and roof. It is necessary to conduct experiments and calculations to determine the transmission factor of the HTL system. It is worth noting that replacing the input devices with ordinary domes to the heliostats could improve the capacity of the system; however, it will require large financial investments for the construction and operation of these systems.

\section{Recommendations and conclusions}

Since simple passive light guide systems of solar tube ${ }^{\circledR}$ type have limited and insufficient length of the light guides, it is better to use active heliostat systems for the reconstruction of the mid- and high-rise buildings.

However, in order to use the light guides to improve the solar exposure conditions of the shaded urban areas, it is necessary to solve the following tasks:

1. Determine the energy and lighting characteristics of the solar radiation carried through the light guide in the short-wave solar radiation spectrum.

2. Develop a methodology for the calculation of solar exposure of the shaded buildings using the light guides.

3. Confirm the experimentally developed methodology.

4. Determine the economic feasibility of the light guides use to improve solar exposure conditions.

5. Create a software package for the calculation of the solar exposure using the light guides.

\section{References}

1. http://www.ssplprints.com/image/109087/advertisement-for-chappuis-patentreflectors-c-1851-1870

2. http://www.heliobus.com/en/

3. W. Wheeler, Apparatus for lighting dwellings or other structures 247, 229 (1881)

4. M.A. Shatelen, Gosenergoizdat, 48 (1949)

5. J. Hecht, Oxford University Press, 14 (2004)

6. D.J. Sterling, Technician's Guide to Fiber optic «Lori», 4 (1998)

7. J.B. Aizenberg, G.B. Bukhman, A.A. Korobko, V.M. Pyategorskiy, Svetotechnika, 3 (2003)

8. J.B. Aizenberg, G.B. Bukhman, A.A. Korobko, V.M. Pyategorskiy, Svetotekhnika, 3 (2016)

9. J.B. Aizenberg, Publ. House "Znack", 182 (2009)

10. J.B. Aizenberg, Spravochnaya khiga po svetotechnike (Znak Moscow, 2008) 
11. D.G. Gritsienko, V.F. Kasyanov, Svetotechnika, 3 (2015)

12. D.G. Gritsienko, V.F. Kasyanov, Light \& Engineering 3, 24-28 (2015)

13. A.Rosemann, H. Kaase, Solar Energy 78(6), $772-780$ (2005)

14. G.M. Knoring, Osvetitelnie ustanovki (Energoizdat, Leningrad, 1981)

15. A.K. Soloviev, Fizika sredi (ASB publishing house, Moscow, 2008) 